\title{
Money Market Deposit Accounts, Super-NOWs and Monetary Policy
}

\author{
JOHN A. TATOM
}

\begin{abstract}
N federal legislation allows depository institutions to offer money market deposit accounts (MMDAs) free of interest rate restrictions. The GarnSt. Germain Depository Institutions Act of 1982 instructs the Depository Institutions Deregulation Com mittee (DIDC) to authorize the new account not later than 60 days after its enactment (October 15, 1982), and requires that the account be "directly equivalent to and competitive with money market mutual funds." In addition, it specifies that the account have no minimum maturity and that it allow up to three preauthorized or automatic transfers and three transfers to third parties (checks) per month. ${ }^{1}$
\end{abstract}

In addition to authorizing this account beginning December 14, 1982, the DIDC issued regulations allowing a super-NOW account to be offered after January 4, 1983; this account allows unlimited checking, or third-party transfers, yet offers an unrestricted interest rate. Both super-NOW and money market deposit accounts require initial and minimum average balances of at least $\$ 2,500$. The primary difference between them is that super-NOWs allow unlimited checking and are counted as transaction accounts for reserve requirement purposes, while money market deposit accounts have limited checking privileges and are not classified as transaction accomnts.

As with prior innovations such as the development of the money market mutual fund (MMMF), the savings deposit with automatic transfer services (ATS), and the negotiable order of withdrawal account (NOW), the new deposits raise important questions about their effects on monetary aggregate measures. Serious concern has been expressed about the continued reliabil-

'See U.S. Congress, Garn-St. Germain Depository Institutions Act of 1982, 97 th Congress, Zd Session, September 8, 1982. In the implementation of the bill, the DIDC interpreted the latter to allow up to six transfers per month, including ap to three checks per montl. ity of monetary aggregates as economic indicators and their usefulness for monetary policy. ${ }^{2}$ Some analysts have concluded that $\mathrm{Ml}$ will be subject to large and unpredictable changes that will adversely affect its relationships with spending and inflation, while M2 will remain unaffected. As a result, it has been suggested that the Federal Reserve should focus more attention on $\mathrm{M} 2$ in the conduct of monetary policy. ${ }^{3}$

The analysis presented here indicates that these concerns are exaggerated. New money market deposit accounts will distort M2, not M1. Super-NOW accounts are not likely to affect either aggregate. Since MI and its interpretation are unlikely to be affected by shifts to money market deposit accounts or superNOW accounts, it should remain as useful for the conduct of monetary policy as it has been in the past.

\section{THW NEW ACOOUNT AND TH

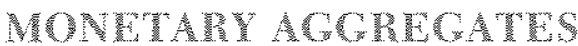

Table 1 presents the definitions of $\mathrm{MI}$ and $\mathrm{M} 2$ and their components as of November 1982, the month

\footnotetext{
"An excellent review of the concerns raised by innovations is that by John M. Berry, "The Fed's Policy Levers Are Becoming Weaker," Washington Post, December 12, 1982. He indicates that some policymakers believe that recent and prospective innovations have rendered $M 1$ "virtually meaningless in the short run," and that $\mathrm{M}_{2}$ is a more iseful target, at least temporarily. See also Edward P. Foldessey, "New Bank Accounts May Force Fed to End Experiment in Monetarism," Wall Street Journal, December 28, 1982.

${ }^{3}$ A shift of emphasis in monetary policy that began in October 1982 was motivated by the same type of argument. Then it was anticipated that the redemptions of All-Savers Certificates, especially in October and November, would distort Ml but not M2. Interest. ingly, a year earlier, the concern with inflows to new All-Savers was that they would lead to a surge in M2, See Daniel $L$. Thomton, "The FOMC in 1981: Monetary Control in a Changing Financial Enviromment," this Review (April 1982), p. 20. The argument that Ml growth was distorted upwark at the end of 1982 due to All Savers redemptions is not examined below, since the pace of $\mathrm{M} 1$ growth in the last three months of 1982 was no larger than occurred from July to October 1982.
} 


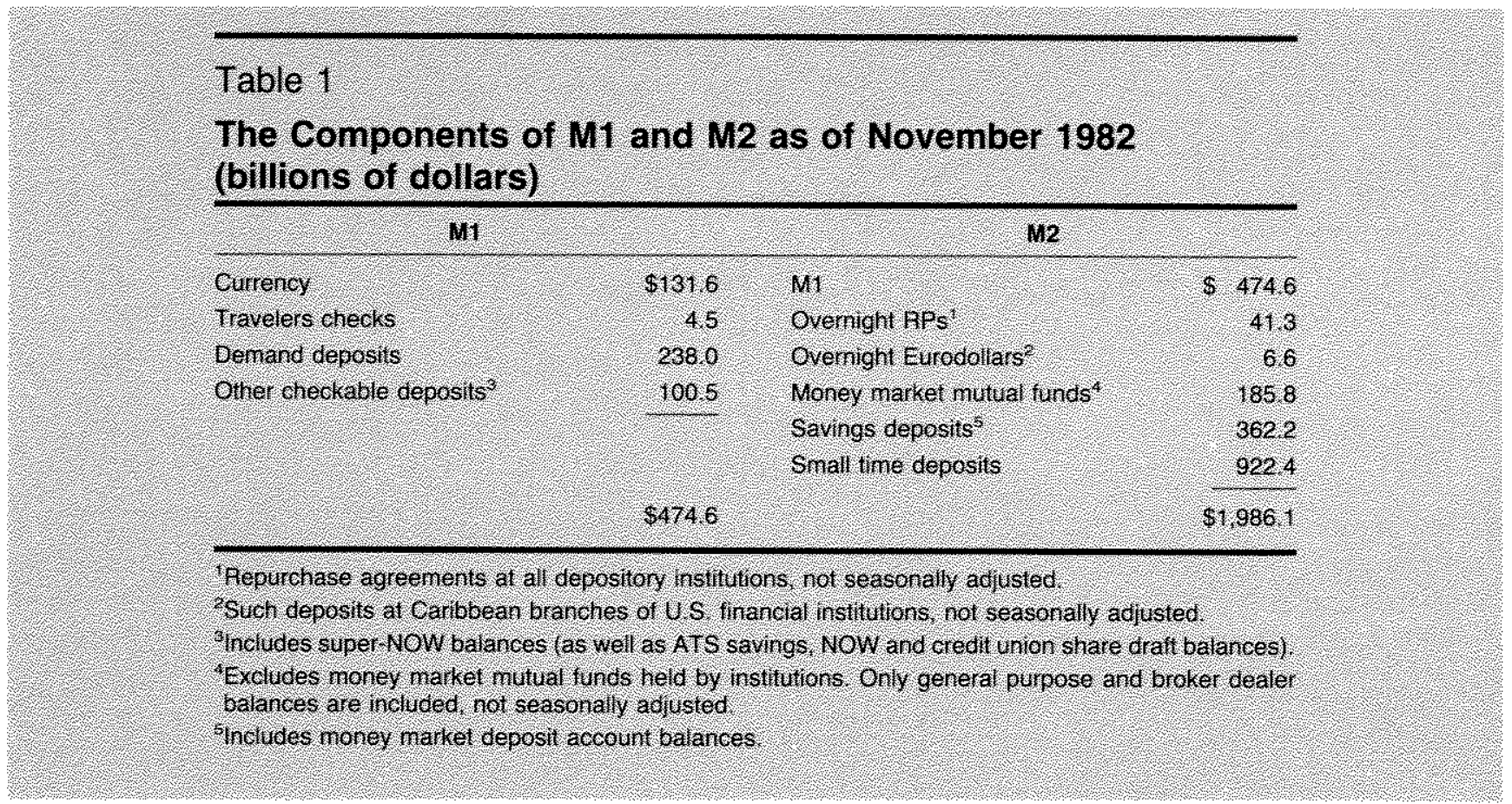

before the introduction of MMDAs. ${ }^{4}$ MMDA balances, which are not transaction balances, are included in $\mathrm{M} 2$, while super-NOW balances are included in $\mathrm{MI}$, since they offer unlimited third-party transfers, just as do demand deposits, ATS balances, NOW deposits and credit union share draft accounts.

\section{The "Sourec of Shifts" Awproach and The mimet of The New Acounts}

A popular means of assessing the effects of these new accounts on the monetary aggregates can be called the "source of shifts" analysis. In this approach, one looks at the items in table 1 and determines the source of the funds that are shifted into each of the new accounts. Of course, it is possible that funds added to one of the new accounts might have come from financial assets not listed in table 1 and this possibility is discussed later. To clarify the use of this particular approach, however, it is convenient to assume that funds shifted into the new accounts come solely from other accounts shown

\footnotetext{
${ }^{4}$ On February 14, 1983, the Board of Governors of the Federal Reserve System announced revisions in the monetary aggregates. These revisions included two definitional changes for $\mathrm{M2}$. First tax-exempt money market mutual funds which previonsly had been excluded from the aggregates were included on the same basis as taxable MMMFs. Second, all IRA/Keough balances at depository institutions and MMMFs were removed from M2. The data used in this study do not incorporate these revisions, but the empirical results should not be affected by them.
}

in table 1 . The net effect for each aggregate can be found by adding the balances in the new account and changes in the balances of the sources of the funds.

The new money market deposit account is included in M2. Consequently, shifts of funds from any other component in table 1 to money market deposit accounts will leave M2 unchanged; of course, shifts from MI deposits to MMDAs will reduce Ml. Thus, if total spending or GNP remains unchanged, shifts to money market deposit accounts from other components of $\mathrm{M} 2$ will not affect the velocity of $\mathrm{M} 2$ (the ratio of GNP to M2), but the velocity of MI the ratio of GNP to M1) will rise if the shifts to MMDAs are associated with a decline in MI.

In the case of super-NOW accounts, shifts of funds among $\mathrm{Ml}$ deposit components will leave both $\mathrm{Ml}$ and M2 totals unaffected. If funds included in M2 but not in MI are shifted to super-NOW accounts, M1 will rise while M2 again is unaffected.

The conclusion of this approach is that M2 will be unaffected by the new accounts, but that $\mathrm{Ml}$ could fall or rise. As a result, MI could be distorted and its movements rendered meaningless during the period of major shifts to these new accounts. This approach indicates that it will have limited use as an indicator of economic activity or a target for monetary policy. On the other hand, since M2 is unaffected, it is argued that its usefulness for policy is unchanged. 


\section{Monelury Asset Fortholios and the Impact of the New Acoounts}

A broader approach is to examine the effects of these new accounts on desired holdings of stocks of monetary assets. In this approach, the actual purchases or sales of financial (or real) assets provide little information about the demand for or supply of MI. For example, when individuals add to their non-transaction balances (i.e, increase their savings), they generally do so initially by reducing their transaction balances; that is, they use currency or checkable deposits. In the "source of shifts" approach, this initial action would be interpreted as a reduction in the demand for transaction balances relative to other financial assets and, therefore, a reduction in $\mathrm{M1}$, with no change in either $\mathrm{M} 2$ or economic activity.

In a more general analysis, this conclusion is not necessarily valid. Since countless individual transactions tend to be offset daily by other transactions by the same or other individuals, the vast majority of these transactions have little effect on financial markets or the nation's economic performance. Only if individuals change the share of their assets held as transaction balances (money) vis a vis savings, or their average money balances relative to income or spending, would there be a meaningful change in economic behavior. In the examination of the new accounts below, considerations from this broader "portfolio approach" generally reverse the "source of shifts" conclusions; the portfolio approach suggests that the new accounts will distort M2 while leaving M1 virtually unaffected.

\section{PROYLCTED MMPAT OP MONEY MARUT IEPOST ACCOUNTS}

The money market deposit account was introduced to allow financial institutions to compete directly for deposits with money market mutual funds. The transaction services available with such accounts are limited, and are generally less than those currently available with money market mutual funds.

In addition to the sources listed in table 1 , households and businesses could switch funds to MMDAs from other asset holdings, including such financial assets as U.S. savings bonds, Treasury bills or other securities. If this were to occur, M2 would rise. ${ }^{5}$ Such

\footnotetext{
${ }^{5}$ The same argument can be carried a step further but is not central to the discussion here. The monetary aggregate M3 includes, in addition to $\mathrm{M} 2$, large time deposits, term repurchase agreements and institutional money market mutual fund balances. Shifts from
}

reallocations in asset holdings are likely only if MMDAs offer a new asset-holding opportunity. Prior to MMDAs, however, asset holders could have held MMMF balances. MMDAs changed the financial environment by allowing a federally-insured, MMMFlike instrument to be held more conveniently at a local depository institution. If the additional convenience and/or insurance are important, M2 will be increased by shifts to MMDAs, while Ml will be unaffected.

The only type of shift to MMDAs that could impinge directly on Ml is a shift of deposits from Ml. Such a shift is unlikely, however. MMDA balances do not provide the transaction services offered by $\mathrm{Ml}$ components and do not change the opportunities available before MMDAs, other than the insurance and conve. nience noted above ${ }^{6}$ Asset holders could have chosen to hold less M1 and more MMMF balances had their higher yields been attractive compared with the lower yield and transaction services of the $M 1$ components. The decision to hold M1 versus MMMF-type balances should be little affected by the availability of money market deposit accounts; their yield and convenience do not appear to offer a substantial improvement over previously available opportunities.

\section{Indirec Effects Produced by Differential Reserve Requirements}

One also must consider whether the shifts of funds to the new money market deposit accounts indirectly affect the monetary aggregates. Different monetary assets have different reserve requirements. Financial innovations that lead to shifts of funds into a new asset could affect the demand for reserves and, given a fixed supply of reserves, indirectly affect the monetary aggregates. Such indirect effects have an important influence on the monetary aggregates because they

\footnotetext{
the latter assets would raise directly $\mathrm{M} 2$ but leave $\mathrm{M} 3$ unaffected. Shifts trom the broad spectrum of financial assets beyond M3, of course, would raise M2 and M3 directly.

Some analysts ray be concerned that MMDA accounts will attract some transaction balances that will continue to be used as transaction balances because of the limited transaction features of these accounts and their unlimited access in person, by messenger or by automatic teller machine. This concern appears to be unfounded; nearly the same opportunity exists but was not used with MMMFs. The same coneern arose for MMMFs, which generally allow unlim ited third party transactions, but often subject to a minimum size. Surveys of check usage of MMMF balances show that a relatively insignificant share of these balances are held in accounts with a turnover rate (ratio of the value of all debits, including checks, to average account balance) as high as that for NoW accounts. The latter, in turn, is less than for demand deposits. The turnover rate on all money market mutual fund shares is lower than for passbook savings deposits at all financial institutions.
} 
influence whether the new accounts affect the various money multipliers. ${ }^{7}$

Personal money market deposit accounts are not subject to reserve requirements. Only nonpersonal money market deposit accounts are subject to reserve requirements, and these requirements are the same as those on nompersonal time and savings balances. The deposit components of $\mathrm{Ml}$, the nonpersonal time and savings components of $\mathrm{M} 2$, and the personal time and savings components of $\mathrm{M} 2$ at member banks of the Federal Reserve System are subject to reserve requirements. To the extent that funds move from such balances to MMDA balances, required reserves are reduced. Given an unchanged stock of reserves, depository institutions would tend to develop excess reserves. To avoid the unnecessary non-interest-bearing reserves, banks can purchase assets, including new loans.

Although the effect on the demand for reserves would be largest for shifts to MMDAs from MI deposit components, such shifts are unlikely to occur. Even if they should occur, the reduction in $M 1$ would tend to be offset exactly by the indirect increase in $\mathrm{Ml}$ arising from the reserve demand effect. The net result is that MI would be unaffected and M2 would be raised just as if the shifts had come from financial assets not in M2. If MMDA funds should come from time and savings deposits, the indirect effects would serve to increase both $\mathrm{MI}$ and $\mathrm{M} 2 .^{8}$

\footnotetext{
"See, for example, the discussion in Jobn A. Tatom and Richard Lang, "Automatic Transfers and The Money Supply Process," this Review (February 1979), pp. 2-10; and John A. Tatom, "Recent Financial Innovations: Have They Distorted the Mearing of MI?" this Review (April 1982), pp. 23-35.

${ }^{8}$ In terus of a framework of the money supply process that uses this Bank's adjusted monetary base, MI usually is affected by MMDA shifts only if there is a change in the adjusted monetary base. In the absence of such a base change, M2 would rise but MI would be unaffected by the shift to MMDA balances. The primary exception is in the case of a change in the public's desired holdings of time and savings deposits at member banks relative to total checkable deposits. The multiplier is not very sensitive to such changes, however, and shifts of such funds to MMMF balances since 1978 have had no appreciable effects on the M1 multiplier over the past five vears. The correlation between monthly changes in the ratio of time and savings deposits at member banks to the total checkable deposit component of $\mathrm{Ml}$ and changes in money market nutual furd balances (general purpose and broker dealer) is 0.003 for the period Jannary 1978 to November 1982 . The cortelation coefficient using quarterly data is 0.19 . These coefficients indicate that shifts to MMMFs have not affected the M1 multiplier through sach a channel in any systematic way. Had such growth in MMMFs been registered in member bank time and savings deposits, however, the multiplier would have been lower and the adjisted monetary base correspondingly higher. This will be the case with MMDAs shifts to MMDAs will have offsetting effects, raising the base and lowering the multiplier during the transition.
}

If, as expected, money market deposit balances come from MMMF balances or other non-reservable components of $\mathrm{M} 2$, neither $\mathrm{M} 1$ nor $\mathrm{M} 2$ will be affected. Finally, if money market deposit accounts arise from portfolio shifts from non-reservable assets not in M2, M2 will increase, while M1 will be unaffected.

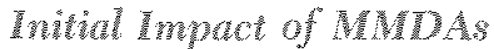

Money market deposit accounts have shown tremendous growth, due in part to the relatively high initial interest rates that depository institutions have offered on them. In the first four weeks, deposits in these accounts grew to $\$ 160$ billion, over 75 percent of the total assets of money market mutual funds. The latter lost about $\$ 25$ billion in share balances from December 8, 1982, to January 12, 1983. At commercial banks, savings deposits fell by $\$ 11.7$ billion over the same period.

A large part of the increase in MMDAs apparently came from shifts of funds from time deposits. At conmercial banks, small and large time deposits fell by $\$ 50.6$ billion from early December to early January. Despite the massive flows of deposits to MMDAs, MI was little changed. For the four weeks ending January $12, \mathrm{Ml}$ averaged $\$ 479.5$ billion, compared with $\$ 477.6$ billion over the prior four weeks. ${ }^{9}$ Weekly information for such a short period is severely limited and cannot be regarded as more than suggestive evidence for the effects of MMDAs on the money supply process and on the interpretation of monetary aggregate movements, however.

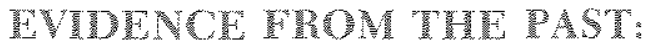 THE TMPCO OF MONEY MARKET MUUAI WUDS ON TH MONETARY AGGPRGATTS}

To assess the various consequences of MMDA shifts, the effects of the advent of money market mutual funds can be examined. Chart 1 shows money market mutual fund balances (general purpose and broker dealer) since the first quarter of 1974 . These balances remained relatively small until 1978 .

\footnotetext{
${ }^{9}$ Since the latter period includes the first week in which superNOWs began, the ahsence of an apparent $\mathrm{MJ}$ effect might be interpreted as a consequence of offsetting effects of MMDAs and super-NOWs on Ml. However, when averages tor the three weeks up to and following the week ending December 15, 1982 are used, MI is virtually unchanged, while MMDAs expanded by $\$ 119.8$ billion.
} 


\section{Chart 1 \\ Money Market Mutual Fund Balances (General Purpose and Broker Dealer)}

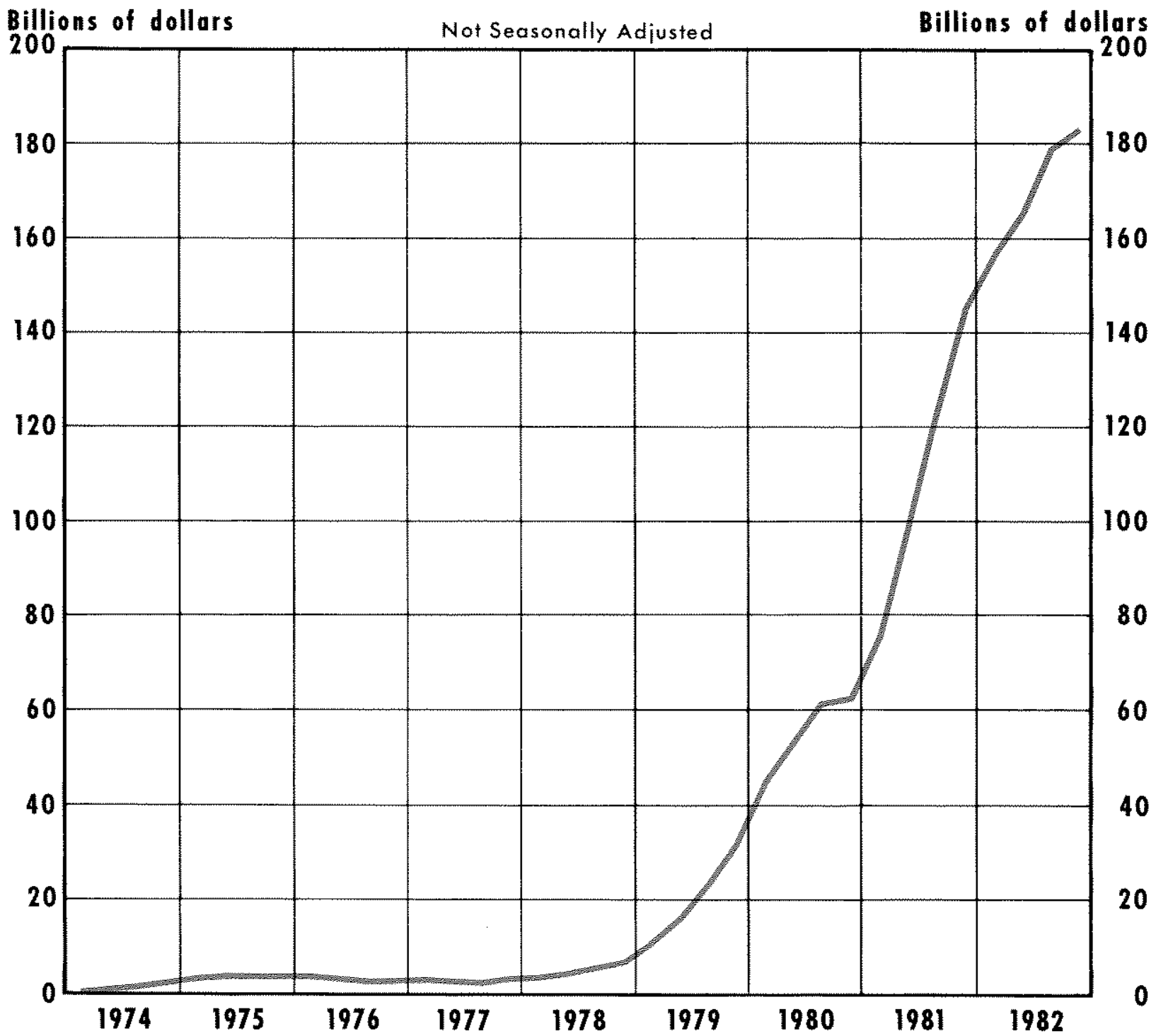

\section{MMW Iffects on the Crowth of the Monelary Aggregates}

Since 1978, when MMMF balances began to expand sharply, monthly changes in money market mutual funds balances have been unrelated to monthly changes in M1 (using not seasonally adjusted data for both series); the correlation coefficient between these changes from January 1978 to November 1982 is 0.03 , which indicates no relationship whatsoever between them. Similarly, monthly changes in MMMF balances are unrelated to monthly changes in currency, demand deposits or other checkable deposits. ${ }^{10}$ The history of

\footnotetext{
The same statistically insignificant relationships are obtained when quarterly changes from the first quarter of 1978 to the third quarter of 1982 are examined. For example, the correlation coefficient between quarterly changes in MMMFs and in $\mathrm{Ml}$ is -0.09 .
} 
MMMF growth from 1978 to the present indicates that M1 growth is unlikely to be affected by the growth of MMDA-type assets.

On the other hand, monthly changes in MMMF balances are correlated positively with monthly changes in $\mathrm{M} 2$; the correlation coefficient is 0.27 , which indicates a statistically significant positive relationship at a 95 percent confidence level. ${ }^{11}$ if all MMMF growth were at the expense of other components of $\mathrm{M} 2$, this correlation would be zero. Thus, the pattern of MMMF growth indicates that the M2 neasure is increased significantly by the growth of MMDA-type assets.

\section{MNIII Wfects on the Component Min of the Monelary Aggregates}

If MMDA-type balances are an attractive alternative to holding deposit components of $\mathrm{M} 1$, then the mix of Ml components should be related to the growth of MMMFs. This could happen if people held relatively large idle checkable deposit balances that they wish to switch to meet the high minimum balances required by money market mutual funds and to obtain their relatively higher yields. Because money market deposit accounts have a higher minimum balance $(\$ 2,500)$ than most money market mutual funds, such an effect could be important for MMDAs.

A measure of the desired mix of $\mathrm{Ml}$ components is the currency ratio, the holdings of currency relative to total checkable deposits. If the introduction of MMDAs causes a shift from checkable deposits, whether "idle" or not, it should show up in a higher currency ratio. In fact, the correlation coefficient between monthly changes in the currency ratio and monthly changes in MMMFs is negative, -0.21 , but not statistically significant at a 95 percent confidence level. For quarterly changes from the first quarter of 1978 to the third quarter of 1982 , the coefficient is -0.03 , again negative but insignificant. Thus, the currency ratio has not been positively affected by the growth of money market mutual fund balances, confrming the previous conclusion that $M 1$ has not been affected by growth in MMDA-type assets.

Chart 2 provides a partial indication of the likely sources of growth in the new money market deposit accoants. This chart looks at the nontransaction com-

\footnotetext{
"For quarterly data from $1 / 1978$ to III/1982, this correhation is 0.43 , which is only significant at a 93 percent confidence level. For seasonally adjusted M2 data, however, the coeffeient is 0,478 , statistically significant at a 95 percent confidence level.
}

ponents of M2, measured relative to the transaction balance measure of money, Ml. The ratio of the nonMl components of M2 to M1 is shown from I/1959 to III/1982, as well as the ratio computed without MMMF balances in the numerator. The broad nontransaction components measure generally rises over the whole period. After 1978, however, the instruments that exclude MMMFs decline sharply from their prior trend. This indicates that the total of nontransaction accounts in $\mathrm{M} 2$ has exhibited a faster trend growth than M1, while the growth in MMMF balances has taken place, in part, at the expense of the other previously existing non-transaction components of M2. ${ }^{12}$

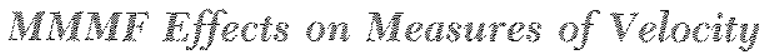

Whether MMDAs affect the meaning of the monetary aggregate measures is indicated by changes in these aggregates relative to total spending or GNP. An analysis of how the velocity of M1-(M2), the ratio of GNP to M1 (M2), has been affected by the growth of MMMF balances provides useful information regarding this question.

The correlation coefficient between quarterly changes in Ml velocity and quarterly changes in MMMF balances from the first quarter of 1978 to the third quarter of $1982,-0.15$, shows no statistically significant relationship between $\mathrm{Ml}$ velocity and MMMF balances. For the same period, the correlation coefficient for changes in $M 2$ velocity is -0.46 , which indicates a statistically significant negative relationship between MMMF balances and M2 velocity. ${ }^{1.3}$ Since 1977 , the velocity of $\mathrm{M} 2$ generally has been pushed down, or its growth rate reduced, by the surge in MMMFs. Thus, contrary to the "source of shifts" view, MMDA-type assets have distorted the relationship be-

\footnotetext{
The correlation between monthy changes in MMMF balances and the other non-Ml components of M2 from January 1978 to November 1982 is -0.48 , using not seasonally adjusted data. This negative correlation is statistically significan at the 95 percent level. For quarterly data from $1 / 1978$ to $17 / 1982$, the same signifcant negative relationship is observed, the correlation coefficient is -0.57 .

${ }^{13} \mathrm{M} 2$ velocity rose sharply from 1977 to 1980 , and in late 1980 and early 1981, despite the rise in MMMFs. The unusually strong growth probably is associated with the sharp rise in interest rates during these periods. The velocity of $\mathrm{M} 2$ is strongly and positively correlated with interest rates. The correlation coefficient for changes in M2 velocity and quarterly changes in the 3-month Treasury bill rate is 0.35 from $\mathrm{IJ} / 1959$ to $\mathrm{IL} / 1982$, while that for $\mathrm{M} 1$ velocity is 0.13 . The former is statistically significant at a 95 percent confidence level, while the latter is not. A recent sharp decline in M2 velocity in 1982 , in part, refects the decline in interest rates.
} 
Chont 2

Non-Transactions Components of M2 Relative to M1

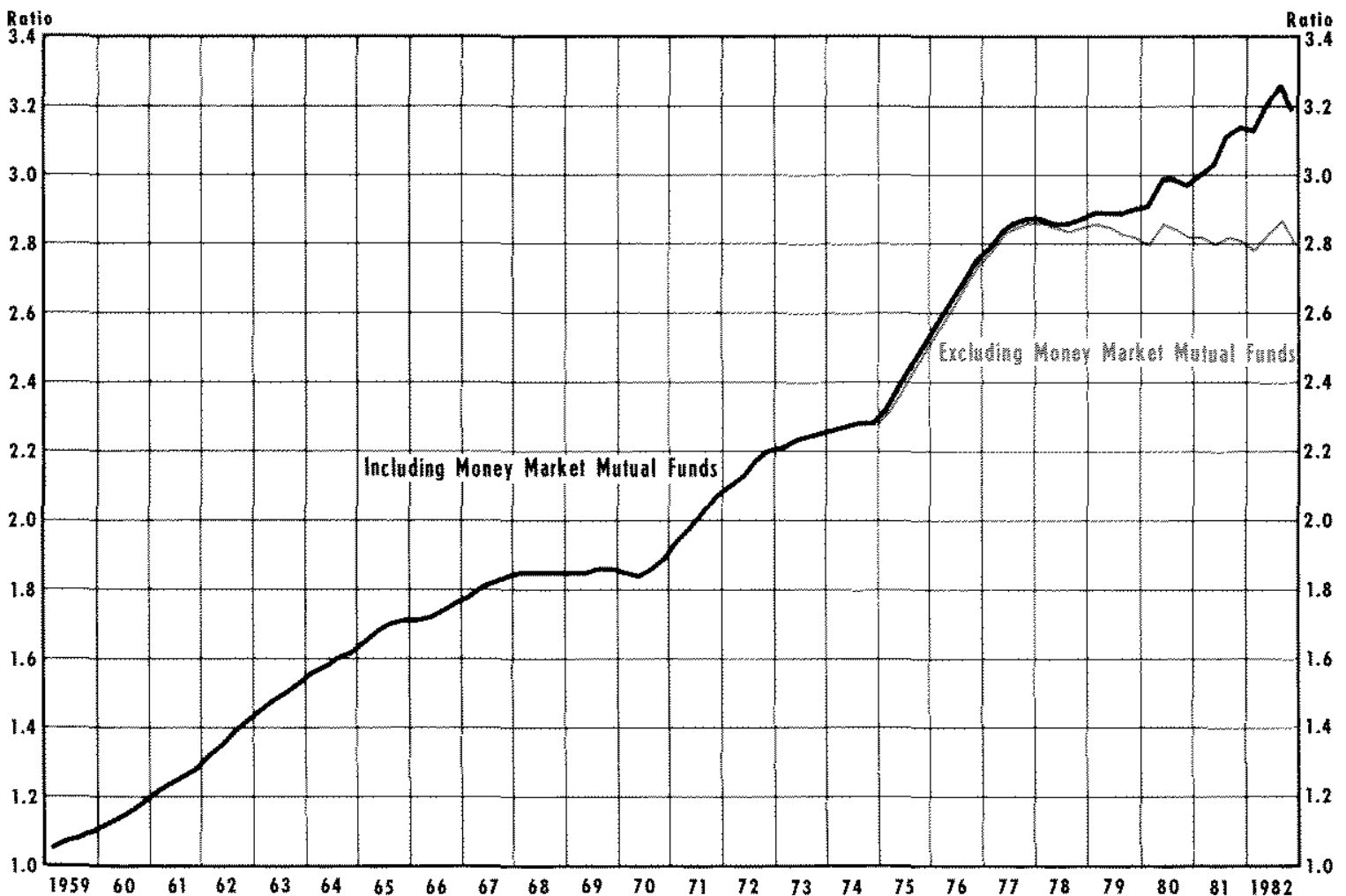

tween M2 and spending, but not between MI and spending.

\section{Summary of thelv MMDA ETects}

The simple correlation evidence from the explosion of money market mutual fund balances over the past Gve years does not support the hypothesis that Ml will be reduced because of shifts from $\mathrm{M} 1$ components to the new MMDA accounts. The evidence associated with the rapid growth of MMMF balances in the past five years indicates that the MI measure will likely be unaffected by MMDA shifts, while M2 will rise. In addition, the evidence indicates that growth in MMDA-type balances, like MMMF balances, will reduce the velocity of $\mathrm{M} 2$, but is not likely to affect $\mathrm{M} 1$ velocity.

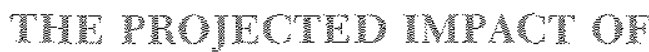 BUPEN-NONS}

The introduction of super-NOW accounts similarly is not without precedent. Super-NOWs are higher- yielding NOW accounts, subject to the same reserve requirements, but with a substantial initial and minimum average balance of $\$ 2,500$ and, in many cases, substantial fees.

NoW accounts, which were permitted nationwide beginning in January 1981, were included in other checkable deposits. Previously, other checkable deposits were principally ATS balances nationwide and NOW account balances in New England, New York and New Jersey, Chart 3 shows the pattern of growth of other checkable deposits from $1 / 1974$ to the present; they did not grow substantially until ATS accotnts were permitted in IV/1978. In December 1980, 9.1 percent of total checkable deposits were held in other checkable deposits (i.e., checkable deposits other than demand deposits). During the first year of nationwide NOW accounts (through December 1981), other checkable deposits surged to 24.6 percent of total checkable deposits. By November 1982, other checkable deposits had risen further, to 29.7 percent of total checkable deposits.

The surge in NOW accounts was limited by restrictions prohibiting businesses from holding such 


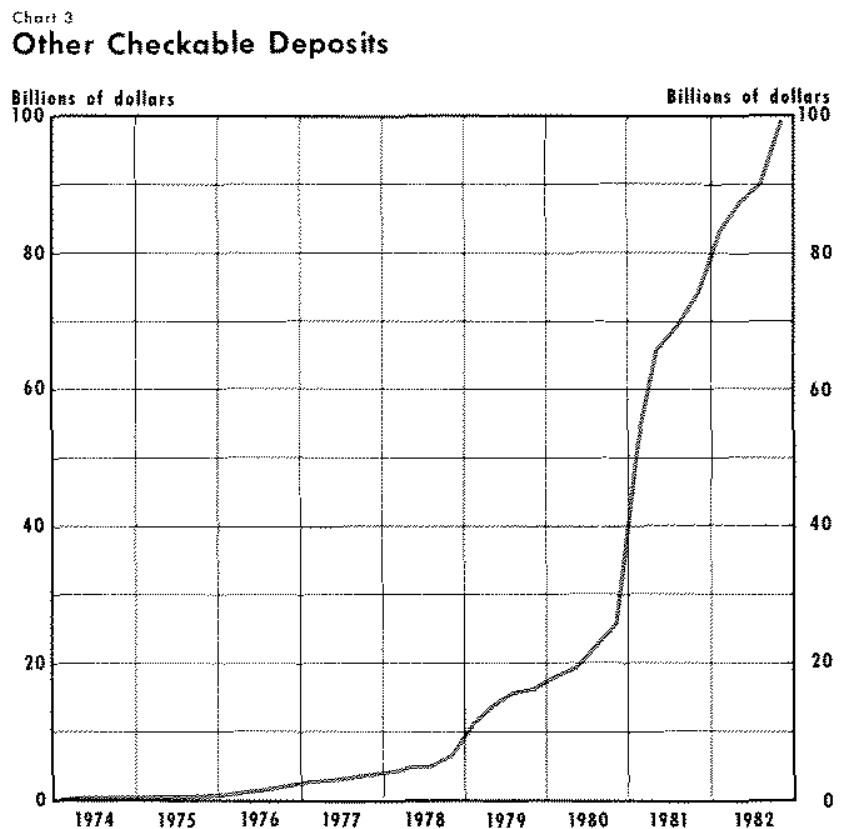

accounts and by the lack of incentives for many depositors. Under existing regulations, the first restriction applies to super-NOW accounts, although the DIDC has asked for public comment on allowing businesses to hold the new super-NOW account. The second restriction, limited incentives, will be even more important with the super-NOW account than the NOW, because of the relatively high minimum balance requirement.

An individual considering holding a super-NOW account must weigh the higher yield on existing average balances currently held in a NOW account against the interest penalty borne on funds that would have to be shifted from higher yielding assets to meet the increased minimum balance requirements. Because super-NOW accounts, unlike MMDA or MMMF accounts, are subject to reserve requirements of about 12 percent, the interest rate paid on super-NOW accomts is likely to be lower than that on MMMFs or MMDAs by about 12 percent of current MMMF rates. In November 1982, this difference was about 1 percentage point; for a range of MMMF rates of 6 percent to 16 percent, this differential or penalty would vary from 72 to 192 basis points. These are clearly significant spreads for otherwise similar assets. Thus, only individuals already holding relatively large checkable deposits, for example, those holding more than $\$ 2,500$ on average, are likely to have an incentive to switch to a super-NOW account.
The primary concern over super-NOWs is not related to shifts from existing NOW accounts, however. Instead, as was the case when nationwide NOW accounts were introduced, the concern is that nontransaction balances will shift into the new accounts, distorting the MI measure. By some estimates, only about 70 to 75 percent of new other checkable deposits in 1981 came from other transaction balances. Consequently, it was thought that as much as 25 to 30 percent of other checkable deposits represented a distortion of the aggregates, especially overstating the growth of the "true" transaction balance component of M1.

The problem with such estimates, as explained earlier, is that the source of the initial funds for a new account may be irrelevant. Previous studies of the effect of NOWs on the money supply process and on the relationship of $\mathrm{M} 1$ to economic performance have shown that shifts to NOW accounts did not distort measured $\mathrm{Ml}$, nor damage its usefulness as an indicator for total spending, inflation or monetary policy developments. ${ }^{14}$ There is no reason to believe that super-NOW accounts will have different effects from those previously observed with NOW accounts.

\section{Addutional Lvidence on the Iffects of NOW Accounts}

Some additional evidence bearing on the likely impact of super-NOWs can be obtained by looking at the correlation between quarterly changes in other checkable deposits since the introduction of ATS accounts (IV/1978) and certain factors that influence the link between monetary policy actions and MI. The factors examined should be affected if desired portfolio holdings are altered by shilts to other checkable deposits such as super-NOWs.

One such factor is the currency ratio. The currency ratio should decline if the demand for total checkable deposits were increased relative to that for currency to meet minimum balance requirements or because the return on other checkable deposits had increased. The correlation coefficient for changes in other checkable deposits and changes in the currency ratio from IV/ 1978 to $111 / 1982$ is -0.27 using seasonally adjusted data, and 0.15 using not seasonally adjusted data;

\footnotetext{
${ }^{14}$ See Tatom, "Recent Financial Innovations: Have They Distorted the Meaning of M1?"; Scott E. Hein, "Short-Run Money Growth Volatility: Evidence of Misbehaving Money Demand?" this Retiew (June/July 1982), pp. 27-36; and Jerry Jordan, "Financial Innovation and Monetary Policy, "in Federal Reserve Bank of St. Louis, Financial Innovations: Their Impact on Monetary Policy and Financial Markets, Proceedings of a Conference held at St. Louis, Missouri, October 1 and 2, 1982 (forthcoming)
} 
neither is statistically significant. Correlation coefficients for quarterly changes in other checkable deposits and quarterly changes in the ratios of commercial bank (and all depository institutions) small (and total) time and savings deposits to total checkable de posits also fail to show any statistically significant negative relationships that might be expected due to shifts of nontransaction balances to measured transaction balances. ${ }^{15}$

Finally, if the growth of other checkable deposits represented such non-transaction balances, the velocm ity of Ml would be negatively and significantly correlated with the growth of other checkable deposits. The correlation coefficient for quarterly changes in M1 velocity and quarterly changes in other checkable deposits over this period is positive, 0.16 , but statistically insignificant. ${ }^{16}$

\section{MPICATIONS TON MONHTHY POYCIOY}

The choice between monetary aggregate targets is influenced by both the controllability of the aggregate and the stability of its relationship to measures of eco. nomic performance, especially total spending or GNP. Typically, on both criteria, Ml is superior to other aggregates in statistical examinations of the historical record. ${ }^{17}$

Despite this evidence, there is widespread concern that recent financial imnovations have affected the meaning or controllability of $\mathrm{M} 1$ and that, during periods of such "turbulence," $\mathrm{M} 2$ is a better policy target than M1. ${ }^{18}$ What is sometimes missed in discus-

The correlation coefficient for quarterly chatages in the ratio of member bank total time and savings deposits to total checkable deposits, not seasonally adjusted, and quarterly changes in other checkable deposits, not seasonally adjusted, is 0.15 , for the period since IV/1978; this also is not statistically signifieant. The Ml and M2 multipliers have been unaffected by changes in other checkable deposits.

${ }^{16}$ The growth of other checkable deposits such as super-NOW balances also is uncorrelated with $\mathrm{M} 2$ velocity movements. The correlation coefficient between quarterly changes in other checkable deposits and M2 velocity is 0.18 for the period from the fourth quarter of 1978 to the third quarter of 1982.

"See 1. W. Hafer, "Much Ado About M2," this Review October 1981), pp. 13-18; and Keith M. Carlson and Scott E. Hen, "Monetary Aggregates as Monetary Indicators," this Review (November 1980), pp. 12-21.

${ }^{18}$ Berry, "The Fed's Policy Levers," provides this condusion but also notes, however, that the velocity of both MI and M2 dropped in 1982, raising some toubt about the usefulness of either aggregate as a target for monetary policy. A decline in velocity; absolately of relative to trend, is not unusual in a recession, however, since measured income declines relative to permanent income See, for example, Milton Friedman, "The Quantity Theory of

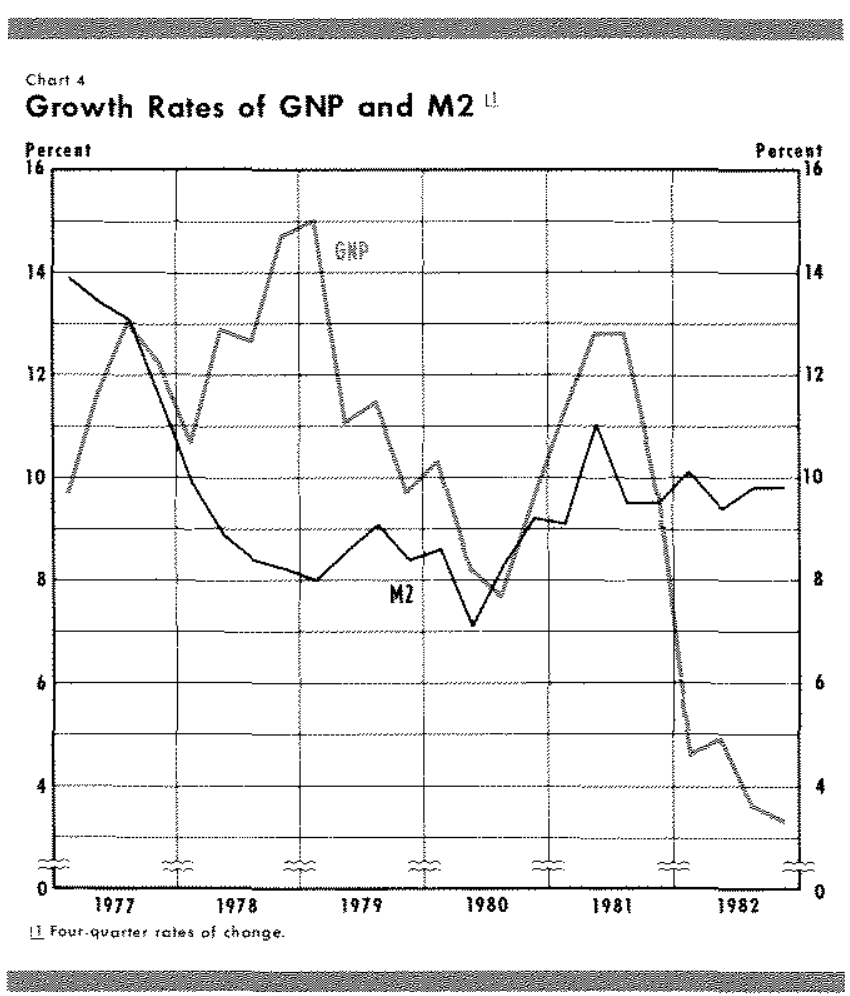

sions of the relative merits of $\mathrm{M} 2$ and $\mathrm{M} 1$, however, is that the 1980 redefinitions of the aggregates changed the $\mathrm{M} 2$ measure substantially while changing $\mathrm{M} 1$ only moderately. The substantial difference between the old and current $\mathrm{M} 2$ measures arises from the inclusion of some financial assets that are competitive with time and savings deposits in the current definition of $\mathrm{M} 2$, especially money market mutual funds. ${ }^{19}$

\section{The Relationship Between the Monetary Aggregates and GNP}

Movements in M2 have been dominated by movements in money market mutual fund balances for several years. As a result, the usefulness of $\mathrm{M} 2$ as an indicator of economic performance has been reduced substantially. Chart 4 shows the annual growth rates of M2 and GNP for four-quarter periods since the first quarter of 1977. Empirical assessment of the relationship of M2 and GNP growth affirm the relationship

Money - A Restatement." in Milton Friednan, ed., Studies in The Quantity Theory of Money (University of Chicago Press, 1956), especially pp. 18-19. The correlation coefficient for quarterly velocity changes and unemployment rate changes is -0.35 and -0.41 for $M 1$ and $M 2$, respectively, from $\mathrm{UI} / 1959$ to III/1982. Both are strongly statistically significant and indicate the negative effect of recessions on velocity.

${ }^{19}$ See R. W. Hafer, "The New Monetary Aggregates," this Retiew (February 1980), pp. 25-32. 
Chars 5

Growth Rates of $M 1$ and $M 2$

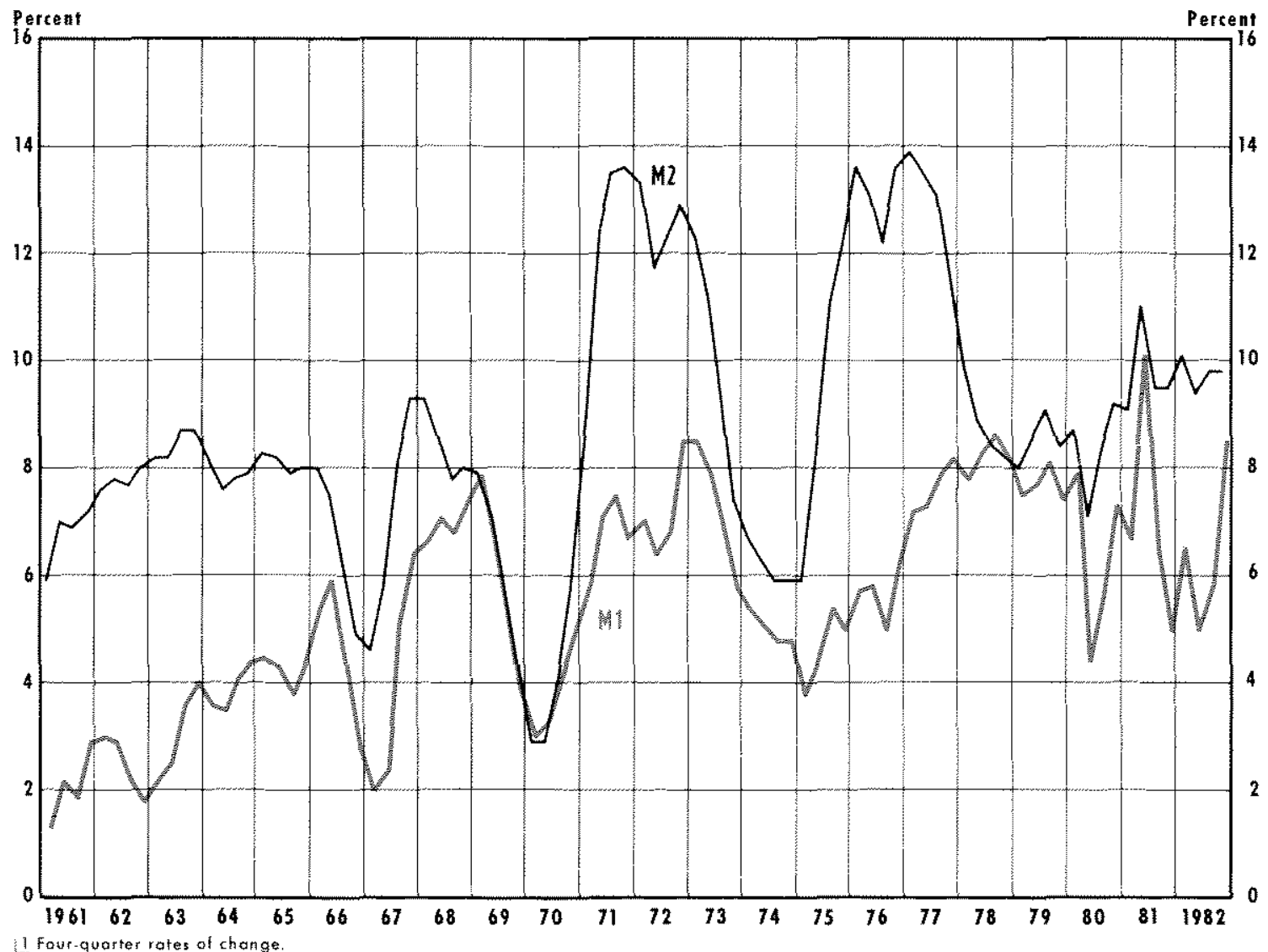

indicated in the chart. There is no correlation between the growth rates of $\mathrm{M} 2$ and GNP over the whole fiveyear period (the correlation coefficient is 0.04 ); over the past three years (I/1979 to III/1982), however, the correlation coefficient $(-0.61)$ is significantly negative at a 95 percent confidence level. ${ }^{20}$

${ }^{20}$ Experiments with reduced-form regression equations bear out the breakdown as well. Hafer "Much Ado Abont M2" presents equations using $\mathrm{M} 1$ or $\mathrm{M} 2$ grow th that indicate the superiority of MI. When a sample period of $[/ / 196]$ to IV/197\% is extended to III/1982, a standard Chow test indicates that the stability of the M2-GNP relationship breaks down. Experiments with the constrained GNP equation presented in the appendix to John $A$. Tatom, "Energy Prices and Short-Run Economic Performance," this Review (January 1981), pp. 3-17, substituting M2 for Ml yield the result that at a 99 percent confidence level the equation with $\mathrm{M} 1$ is statle after $197 \mathrm{7}$, but that with $\mathrm{M} 2$ is not. Simulations of the IV/1977 equation yield systematic and relatively large underestimates of GNP growth wntil $/ / 1981$, then systematie and large overestimates of GNP growth to IJE/1982 Of the 19 quarters simulated, six of the errors are greater than twoe the standard error of the equation estimated and the root mean square error of the estimates is 5.10 percent, compared with an in-sample standart error of 2.80 percent.
In contrast, the growth rate of GNP is highly and significantly positively related to the growth rate of M1, both for the entire five-year period (the correlation coefficient is 0.67 ), and for the $1 / 1979$ to $111 / 1982$ subperiod (the correlation coefficient is 0,58 ). ${ }^{21}$

\section{The Conmolwhily of Monewry Agregenes}

The problem with using M2 as an indicator of economic performance is reflected in the breakdown of the relationship between $\mathrm{Ml}$ and $\mathrm{M} 2,{ }^{22}$ Chart 5 shows

\footnotetext{
${ }^{21}$ For the conventional contrasting vew, see Berry, "The Fed's Policy Levers." He notes that the relationship of M2 to GNP has been "quite stable and trendless with, say a 10 percent increase in M2, almost always associated with about a 10 percent increase in GNP"

${ }^{27}$ The breakdown in the positive and strong relationship for the past several years is not umprecedented. There was no relationshin during 1962-66 when 12 growth changed little, but Ml and GNP growth accelerated starply; the correlation coefficient for $\mathrm{M} 2$ and GNP growth over this period is 0,24 , not statistically significant at conventional tevels.
} 
Chart

M1 and M2 Multipliers

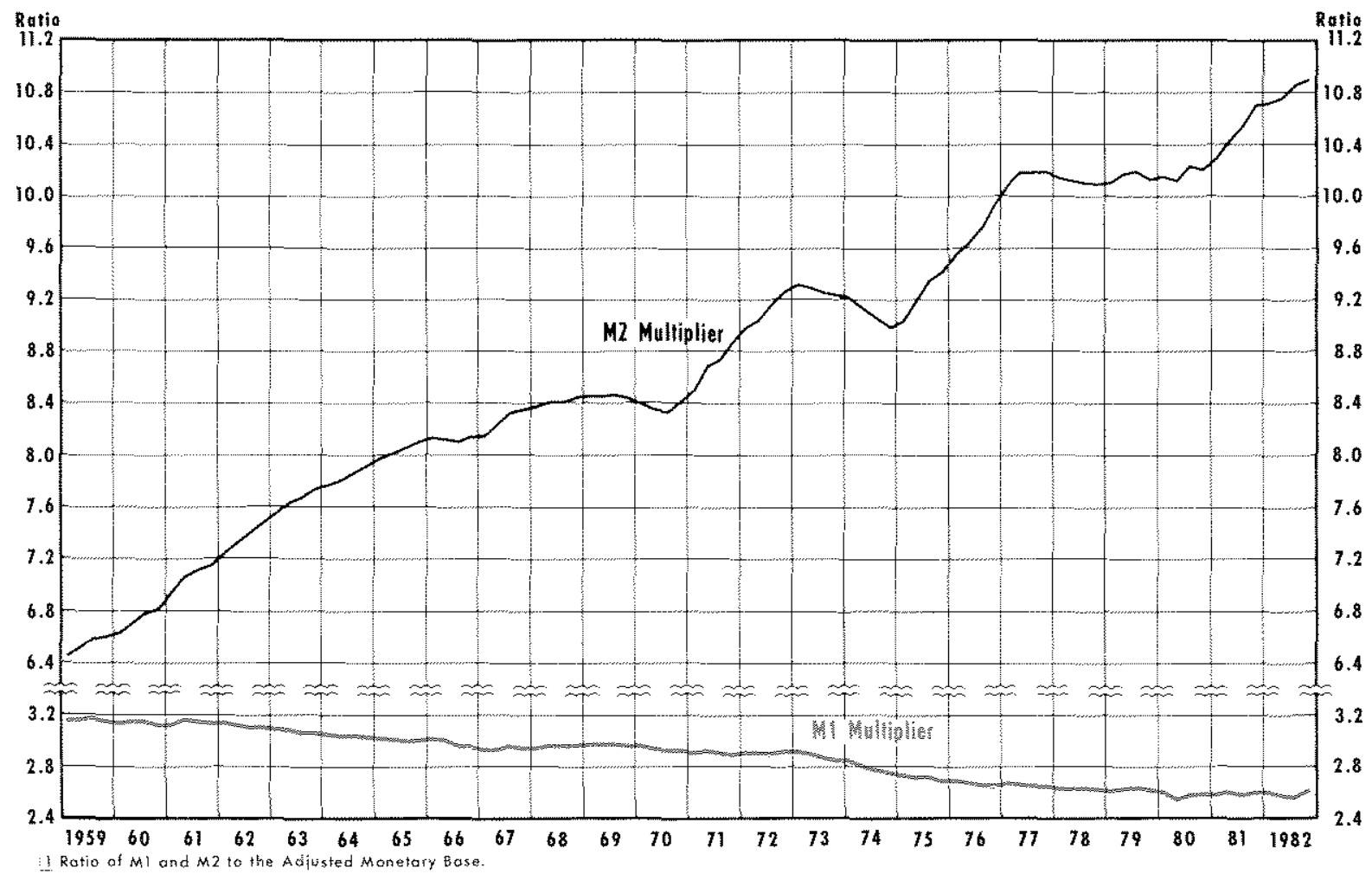

the annual growth rate of M1 and M2 for four-quarter periods since 1960 . Until $197 \%$, the growth rates are highly positively cortelated the correlation coefficient is 0.65$){ }^{23}$ This relationslip disappears after 1976; the correlation over the period $1 / 1977$ to $1 / 1 / 1982$ drops to 0.23 , which indicates the absence of a statistically meaningful relationship.

This evidence provides some insight into the issue of the relative controllability of the monetary aggregates; this issue is crucial in the choice of a monetary policy target. The central bank directly controls only its own portolio, so it can detemine precisely only the monetary base. If the relationship between the base and monetary aggregates is unstable or even highly variable, the achievement of policy objectives is more difficalt. In this case, the difficulty would be hitting the

\footnotetext{
${ }^{23}$ Kenneth C. Froewiss, Financial Market Perspective, GoldmanSachs Econonics (Decenber 1982) p. 3, shows that the srowth in $\mathrm{Ml}$ phis the savings components of $\mathrm{M} 2$, has been inversely related to that of the remander of $\mathrm{M} 2$ since mid-1978. He argues that this is evidence that $\mathrm{M} 2$ is no longer a reliable guide to monetary policy.
}

target successfully. M2 is subject to substantially higher control errors than M1. ${ }^{24}$ Over the past several years, this has been apparent in the disparate behavior of $\mathrm{M} 1$ and $\mathrm{M} 2$.

Further evidence on this issue is avalable from the analysis of the ratios of M1 and M2 to the adjusted monetary base, the M1 and M2 multipliers. These multipliers are shown in chart 6 from $1 / 1959$ to III

\footnotetext{
${ }^{27}$ It slould be noted, however, that in shortmen control experiments, the error dispersion statistics for current-nonth aggregate projections have been found to be smaller for $\mathrm{M} 2$ than for $\mathrm{M}$ issing both judgmental forecast and the Rasche-Johannes mutiplier forecasting method. See David Lindsey, at al. "Monetary Control Experience Under The New Operating Procedures," in Board of Govemors of the Federal heserve System. Federal Reserve Staf Study, Net Monetary Control Procedures (Febriary 1981\%, pp. 1-102

The conclusion in the text is based on quarterly estimates of the relationship betweer monetary growth rates and the growth rate of the adjusted monetary base, such as those in fohn $A$. Tatom, "Money Stock Control Under Alternative Definitions of Money," this Review November 1979), pp. 399, or Hafer, "Much Ado About M2, "where the standard error of aggregates is higher for M2 than for $M 1$
} 
1982. The earlier analysis indicates that NOWs did not affect the components of the M1 or M2 multiplier, while the growth of MMDA-type assets affected only M2. A direct correlation analysis of the multipliers bears out these findings. The correlation coefficient between quarterly changes in the M2 multiplier and quarterly changes in MMMF balances since I/1978 is strongly and significantly positive (0.82); changes in the M1 multiplier, on the other hand, are unrelated to movements in MMMFs (the correlation coefficient for the same period is 0.12 ). Changes in other checkable deposits have had no significant effect on either the MI or M2 multiplier over the same period; the correlation coefficient equals 0.23 and 0.38 , respectively. ${ }^{25}$

\section{Summary}

Based on the evidence above, it appears likely that the growth of money market deposit accounts will complicate efforts to control M2. The new accounts will tend to raise the $\mathrm{M} 2$ multiplier and reduce the $\mathrm{M} 2$ velocity, making $\mathrm{M} 2$ more difficult to control and to interpret for policy purposes.

The new accounts do not appear to pose a problem for M1. Its controllability and its relationship to spending are not likely to be affected by the changes according to the evidence from similar recent institutional changes.

\section{CONGLUSTON}

Strong concern has been expressed that newly authorized financial instruments at depository institutions will substantially alter $\mathrm{Ml}$, thus reducing its usefulness as a target for conducting monetary policy. In particular, the current concern is that $\mathrm{M} 1$ will be either pushed upward by additions of idle or non-transaction balances to meet the higher minimum for super-NOW accounts, or pushed downward by shifts of idle or non-transaction balances from demand and NOW de-

\footnotetext{
${ }^{25}$ The $\mathrm{M} 2$ multiplier is negatively related to movements in shorttem interest rates. From I/1978 to IIU/1982, the correlation coefficient between changes in the M2 multiplier and those of the 4 - to 6-month commercial paper rate is -0.47 . The M1 multiplier is not statistically correlated with changes in rates.
}

posits to MMDAs. Since such shifting is primarily between assets within the M2 measure, it has been widely asserted that the shifts do not affect the measure of $\mathrm{M} 2$ and, by implication, will not distort its meaning or usefulness for the conduct of monetary policy.

A broader view of the money supply process reaches the opposite conclusions. The newly created money market deposit accounts are non-reservable deposits with limited transaction services and are quite similar, in practice as well as in legislative intent, to money market mutual funds. The principal differences are federal insurance and geographic convenience. Similarly, super-NOW accounts are virtually identical to NOW accounts, except that a $\$ 2,500$ minimum balance is required by law and the instrument is free of rate regulation.

Money market mutual fund-type assets, like money market deposit accounts, have no effect on MI or its velocity. Increases in such assets do tend to raise M2, however, and to reduce its velocity. Super-NOWs are similar to other checkable deposits and are unlikely to affect M1 or M2 measures or their relationships to spending. In principle, the higher yields on superNOWs compared with other transaction balances could lower currency demand relative to total transaction deposits, thereby increasing both the demand for M1 and its multiplier. The evidence from the introduction of ATS and, later, NOW accounts provides no support for this conjecture, however.

Finally, it does not appear that M2 is likely to be superior to $\mathrm{Ml}$ as a target for conducting monetary policy. The conventional view that the M2-GNP relationship is both statistically significant and stable has not been supported by the experience over the past several years. ${ }^{26}$

\footnotetext{
${ }^{26}$ The argument here is not that monetary policy cannot be conducted successfitly using an M2 targeting procedure. The evi dence cited above only shows that MMDA acconnts are likely to raise $\mathrm{M} 2$ growth relative to monetary policy measures like the adjusted monetary base, and relative to spending. Continuous monitoring of the effect of new accounts on $\mathrm{M} 2$, as well as successful monitoring of the effect of interest rate movements on the supply and demand for $\mathrm{M}_{2}$, in principle, could allow movements in the M2 target range that would be compatible with the attainment of policy objectives.
} 